\title{
Early pregnancy growth and pregnancy outcome in twin pregnancies
}

\author{
T Dias $^{1}$, A Bhide ${ }^{1}$, B Thilaganathan ${ }^{1}$ \\ (Index words: twins, crown-rump length, chorionicity, birth weight discordance, fetal loss)
}

\begin{abstract}
Objectives The objective of this study was to determine the association of crown-rump length (CRL) discrepancy in monochorionic and dichorionic twins with subsequent pregnancy outcomes.
\end{abstract}

Method A retrospective analytical study was performed among 660 twin pregnancies over 12 years in one fetal medicine tertiary referral center in the United Kingdom. A literature search was performed to identify all reports in the English language literature in this topic between 1998 and 2009.

Results Five hundred and six dichorionic and 154 monochorionic twin pregnancies were studied. Median percentage CRL discordance in monochorionic and dichorionic pregnancies was not different $(3.9 \pm 8.34$, range $0-59$ and $3.2 \pm 5.65$ range $0-37.5$, respectively, $p=0.225$ ). Single or double fetal loss was higher in monochorionic twins than the dichorionic twins. Loss rate was $17.53 \%(27)$ and $3.95 \%(20)$ respectively $(p=$ $<.0001)$. CRL disparity and birth weight discordancy showed statistically significant correlation (Spearman's rho, $p=0.040$ ). Statistically significant correlation was seen between percentage CRL disparity and pregnancy loss rate $(p=0.008)$. However, the sensitivity of this CRL discrepancy to detect subsequent fetal loss or birth weight discordance is poor.

Interpretation CRL discrepancy is independent of chorionicity in twins. CRL discrepancy is correlated to subsequent pregnancy loss and birth weight discordance, but the clinical utility of this observation is limited. The difference in twin CRL at 11-14 weeks is likely to represent physiological variation in a majority of cases.

Ceylon Medical Journal 2010; 55: 80-4

\section{Introduction}

Twins are responsible for $1-3 \%$ of total pregnancies [1]. Out of all twins, 2/3rds are dizygotic and invariably dichorionic. Embryonic splitting occurs in about 1/3rd of monozygotic twins within the first three days after fertilization, and these also result in dichorionic twins. Therefore about $80 \%$ of twin pregnancies are dichorionic. Monochorionic twins are responsible for $20 \%$ of all twin gestations and results from late embryonic splitting after 3 days of monozygotic conception [1].
Irrespective of the period of gestation, twins carry a high risk of pregnancy associated complications [2]. It has been recognised that early fetal growth of individual foetus within the twin pregnancy is not uniform [2, 3]. According to the National Institute of Health and Clinical Excellence guidelines pregnancies are often dated by first trimester crown-rump length (CRL), so that early growth problems can be identified as early as 11-14 weeks [4]. Discordant early fetal growth of twin pregnancy has been associated with late complications of pregnancy such as pregnancy loss and discordant birth weight [2, 5].

Discordant birth weight is one of the recognised complications of twin pregnancies. It carries a higher risk of perinatal morbidity and mortality of the twins with or without fetal growth restriction [6,7]. Growth discordancy has been classified as mild or severe according to the percentage difference of birth weight, $15 \%$ and $25 \%$ respectively [8].

There is no consensus whether this important complication could be predicted in early pregnancy by ultrasonography [5]. In most instances, subtle CRL differences may not be clinically significant [9]. However it has been documented that early growth may lead to adverse pregnancy outcome [10].

The aim of this study was to determine the association of CRL discrepancy and pregnancy outcome in monochorionic and dichorionic twins.

\section{Method}

This is a retrospective analytical study which was performed in one fetal medicine tertiary referral center in the UK. We retrieved all the ultrasound data of twin pregnancies over a period of 12 years between December 1996 and September 2009 from a purpose-built data base. All the first trimester twin pregnancy data between 11 and 14 weeks were reviewed and twin pregnancies with crown rump length between $45 \mathrm{~mm}$ and $84 \mathrm{~mm}$ were included. The twin pregnancies referred from other hospitals were excluded to avoid referral bias. The pregnancy was dated by the CRL of the bigger twin in spontaneous conceptions and date of embryo transfer in in-vitro fertilization (IVF). Chorionicity was assigned at the first trimester scan by the presence of 'lambda' sign for the dichorionic twins

${ }^{1}$ Fetal Medicine Unit, Academic Department of Obstetrics and Gynaecology, St George's University of London, UK.

Correspondence: TD, e-mail <thiran_dias@yahoo.com>. Received 7 January and accepted 3 April 2010. Competing interests: none declared. 
and ' $\mathrm{T}$ ' sign for the monochorionic twins [11]. Outcome of the pregnancy was collected from the hospital records, patients and the general practitioners.

The inter-twin CRL discrepancy was calculated by subtracting CRL of smaller twin (CRL-S) from the CRL of larger twin (CRL-L). Furthermore a percentage difference of the CRL was computed by dividing CRL discrepancy by CRL of the large twin. Fetal loss and birth weight discordance was reported as outcome measures. Miscarriage or stillbirth of one or both twins was defined as a fetal loss. Fetal losses were counted per pregnancy and not per fetus. Birth-weight difference of twins calculated as the difference in the weights expressed as a percentage of that of the bigger twin. Birth weight discordance of $\geq 15 \%$ was considered as a grade I (mild) discordance and $\geq 25 \%$ considered grade II [8]. A literature search was performed to identify all reports in the English language literature (Medline, National Library of Medicine) on this topic between 1998 and 2009.

Non parametric continuous data were compared by Mann-Whitney U-test and correlation between variables was assessed by Spearman's rho test. Chi-square test was used for categorical data. All $p$-values reported are two tailed and a level of 0.05 or less was considered statistically significant. Analysis was performed using SPSS version 15.0 (SPSS Inc., Chicago, IL, USA). Approval for the study was obtained from the local ethics review committee.

\section{Results}

There were 660 twin gestations with follow up details to identify the subsequent outcome. Some of these cases have been included in a previous report [8]. Of these twin pregnancies 506 were dichorionic and 154 were monochorionic twins.

There was no difference between median percentage CRL discordance in monochorionic versus dichorionic

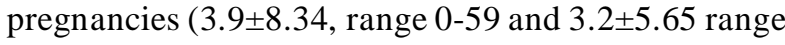
0 -37.5, respectively, $p=0$. 225). Table 1 shows the 5 th, 10th, 50th, 90th and 95th centiles for percentage CRL discrepancy for all twins (Table 1).

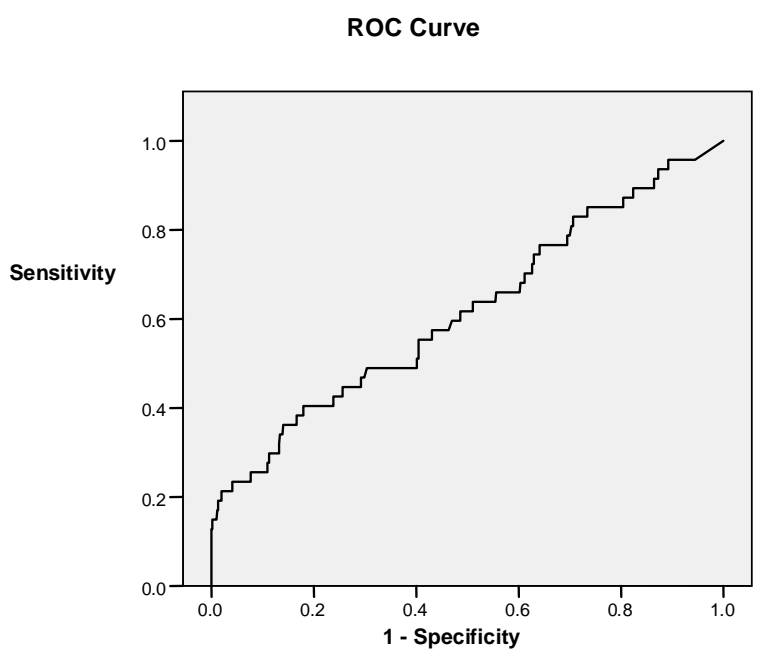

Figure 1. Receiver operating characteristic curve for percentage CRL discordance and pregnancy loss

A statistically significant higher incidence of single or double fetal loss was seen in monochorionic twins than in dichorionic twins. Loss rate was $17.53 \%$ (27) and 3.95\% (20) $(p=<.0001)$ in monochorionic and dichorionic twins respectively. The pregnancy loss was further evaluated in relation to the percentage CRL discrepancy by constructing a receiver operating characteristic (ROC) curve. This ROC curve (Figure 1) had an area under the curve of 0.616 (95\% CI 0.524-0.709) and revealed a statistically significant correlation between percentage CRL disparity and pregnancy loss rate $(p=0.008)$.

Table 1. Population centiles for inter-twin crown rump length (CRL) discrepancy and sensitivities/ specificities for predicting fetal loss and birth-weight discordance for all twins.

\begin{tabular}{lccccccc}
\hline \multicolumn{2}{l}{ Percentage CRL discrepancy } & \multicolumn{2}{c}{ Pregnancy loss } & \multicolumn{2}{c}{$\begin{array}{c}\text { Birth weight discordance } \\
\text { Grade I }\end{array}$} & $\begin{array}{c}\text { Birth weight discordance } \\
\text { Grade II }\end{array}$ \\
\hline Centile & \% discrepancy & Sensitivity & Specificity & Sensitivity & Specificity & Sensitivity Specificity \\
5th centile & 0.0 & 95.7 & 5.5 & 96.7 & 6.6 & 100 & 6.4 \\
10th centile & 0.5 & 95.7 & 10.6 & 92.2 & 12.1 & 95.3 & 11.8 \\
50th centile & 3.3 & 65 & 52 & 58.8 & 51.5 & 67.2 & 50.7 \\
90th centile & 10.1 & 25 & 91.6 & 15.7 & 93.6 & 20.3 & 92.2 \\
95th centile & 12.1 & 25 & 95.7 & 7.2 & 97.8 & 6.3 & 96.7 \\
\hline
\end{tabular}


Birth weight discordance (grade I and II) of monochorionic and dichorionic twins did not show statistically significant difference (median percentage birth weight discordancy $8.0 \%$ (range 0 - 57) and $9.4 \%$ (range 0-69) respectively, $p=0.549$ ). However, Grade II birth weight discordance was more common in monochorionic twins and this difference in the prevalence was statistically significant $\left(\mathrm{X}^{2}-7.051\right.$, $p=0.008)$.

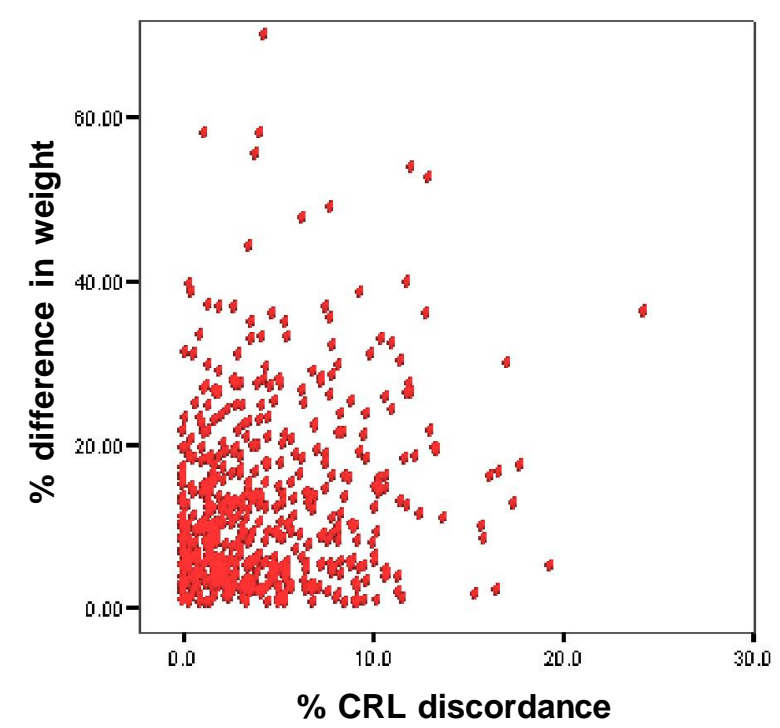

Figure 2. Correlation of percentage CRL discordance and percentage birth weight difference.
CRL disparity and birth weight discordancy showed statistically significant correlation (Spearman's rho, $p=0.040$ ) (Figure 2). This correlation was further analyzed with respect to degree of birth weight discordance using ROC curves (Figures 3 and 4). The area under the curve for correlation between CRL discrepancy and grade 1 and grade 2 birth weight discordance is 0.592 (95\% CI, 0.537 $0.649, p=0.001$ ) and 0.626 (95\% CI 0.553-0.698, $p=0.001$ ) respectively. Summary of recent publications on CRL disparity and pregnancy outcomes is given in Table 2.

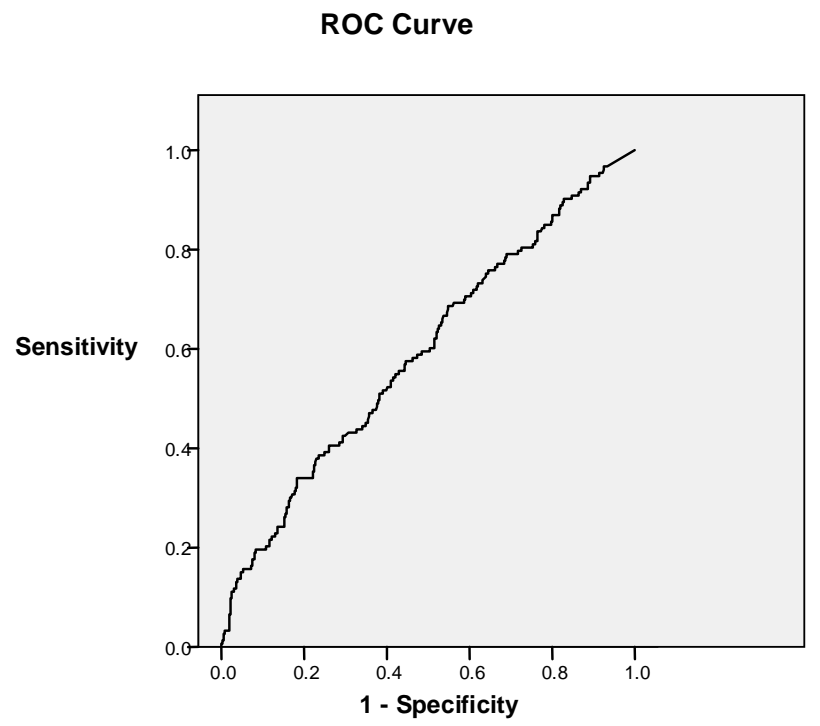

Figure 3. Receiver operating characteristic curve for percentage CRL discordance and Grade 1 discordance (15\% or more).

\section{ROC Curve}

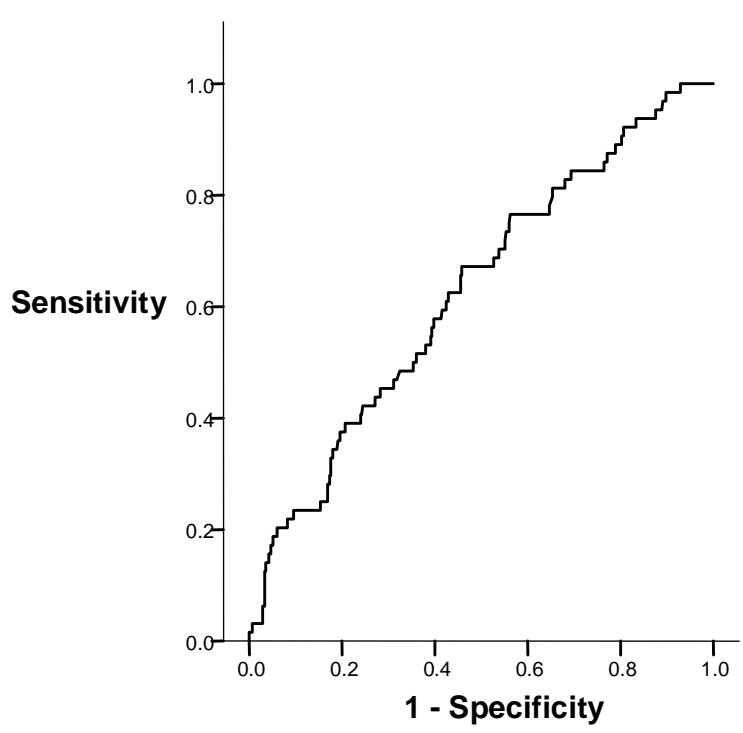

Figure 4. Receiver operating characteristic curve for percentage CRL discordance and Grade 2 discordance ( $25 \%$ or more). 
Table 2. Survey of literature in CRL discrepancy and pregnancy outcome in twins

\begin{tabular}{|c|c|c|c|c|c|c|c|}
\hline Author & Year & $\begin{array}{l}\text { No } \\
\text { cases }\end{array}$ & $\begin{array}{l}\text { Type of } \\
\text { twins }\end{array}$ & $\begin{array}{l}\text { Gestation at } \\
\text { the scan }\end{array}$ & $\begin{array}{l}\text { Twin used } \\
\text { for dating }\end{array}$ & $\begin{array}{l}\text { Outcome } \\
\text { measures }\end{array}$ & Conclusions \\
\hline Sebire & 1998 & 539 & DC/MC & 10 to 14 & Larger & $\begin{array}{l}\text { Birth weight } \\
\text { discordance }\end{array}$ & $\begin{array}{l}\text { There is no significant } \\
\text { correlation in CRL discrepancy } \\
\text { and birth weight discordancy in } \\
\text { mono and dichorionic twins }\end{array}$ \\
\hline $\begin{array}{l}\text { Kalish } \\
\text { et al }\end{array}$ & 2003 & 130 & DC & 11 to 14 & Larger & $\begin{array}{l}\text { Birth weight } \\
\text { discordance }\end{array}$ & $\begin{array}{l}\text { CRL disparity correlates } \\
\text { positively with birth weight } \\
\text { discordance }\end{array}$ \\
\hline $\begin{array}{l}\text { Salomon } \\
\text { et al }\end{array}$ & 2005 & 187 & $\mathrm{MC} / \mathrm{DC}$ & 11 to 14 & $\begin{array}{l}\text { Larger/ } \\
\text { Oocyte } \\
\text { retrieval }\end{array}$ & $\begin{array}{l}\text { Pregnancy } \\
\text { loss/Birth } \\
\text { weight } \\
\text { discordance }\end{array}$ & $\begin{array}{l}\text { No correlation between CRL } \\
\text { discrepancy and birth weight } \\
\text { discrepancy }\end{array}$ \\
\hline $\begin{array}{l}\text { Tai J } \\
\text { et al }\end{array}$ & 2007 & 178 & DC/MC & 7 to 14 & & $\begin{array}{l}\text { Birth weight } \\
\text { discordance/ } \\
\text { SGA at least } \\
\text { in one of the } \\
\text { twins }\end{array}$ & $\begin{array}{l}\text { The CRL disparity significantly } \\
\text { correlates with birth weight } \\
\text { discrepancy }\end{array}$ \\
\hline $\begin{array}{l}\text { Banks } \\
\text { et al }\end{array}$ & 2008 & 108 & DC & 10 to 14 & Larger & $\begin{array}{l}\text { Birth weight } \\
\text { discordance }\end{array}$ & $\begin{array}{l}\text { First trimester biometric } \\
\text { disparity performs poorly as a } \\
\text { screening test for birth weight } \\
\text { discordance }\end{array}$ \\
\hline $\begin{array}{l}\text { Bhide } \\
\text { et al }\end{array}$ & 2009 & 507 & MC/DC & 11 to 14 & Larger & $\begin{array}{l}\text { Pregnancy } \\
\text { loss / Birth } \\
\text { weight } \\
\text { discordance }\end{array}$ & $\begin{array}{l}\text { CRL discrepancy was } \\
\text { significantly correlated } \\
\text { with birth-weight discordance in } \\
\text { twins/ first-trimester CRL } \\
\text { discrepancy is of limited value } \\
\text { in predicting adverse outcomes }\end{array}$ \\
\hline $\begin{array}{l}\text { Bora } \\
\text { et al }\end{array}$ & 2009 & 77 & DC/MC & 7 to 10 & $\begin{array}{l}\text { Larger/ } \\
\text { embryo } \\
\text { transfer }\end{array}$ & $\begin{array}{l}\text { Single fetal } \\
\text { loss 11-14 } \\
\text { weeks scan }\end{array}$ & $\begin{array}{l}\text { Significant relationship between } \\
\text { CRL discrepancy at } 7+0 \text { to } 9+6 \\
\text { weeks and the likelihood of } \\
\text { subsequent single intrauterine } \\
\text { foetal loss }\end{array}$ \\
\hline
\end{tabular}

\section{Discussion}

Discordance in the crown rump length of twins has been reported as early as 7 weeks and this difference persists at 11 to 14 weeks [12]. Our results show that CRL discrepancy does not significantly differ according to chorionicity. None of the studies that reported CRL discrepancy between 10-14 weeks have shown any difference between monochorionic and dichorionic twins $[1,5,8-9]$. We can therefore conclude that early pregnancy growth has not been affected by chorionicity.

Pregnancy complications of the monochorionic twins are higher than the dichorionic pregnancies. Twin to twin transfusion syndrome, discordant fetal anomalies, twin reverse arterial perfusion (TRAP) and discordant fetal growth restriction are recognised reasons for fetal loss in monochorionic pregnancies [13]. An association of early CRL difference and pregnancy outcome is important to determine since it may help in counselling prospective parents. Even though the correlation between CRL discordance and pregnancy loss in twins is statistically significant, its clinical relevance is limited because most of the pregnancy losses happen without a significant CRL discrepancy. Sensitivity of CRL discrepancy as a predictor to determine pregnancy loss is low (Table 1 ).

Inter-twin birth weight discordance has been shown to be associated with perinatal mortality and morbidity 
independent of chorionicity [1, 14-15] and length of the pregnancy [16]. Recent evidence has demonstrated a relationship between discordant growth and several parameters of adverse outcome, including intrauterine and neonatal mortality, presence of malformations, and small for gestational age $[17,18]$. Our study revealed that CRL discrepancy significantly correlates with the birth weight discordance. However, the sensitivity of this CRL discrepancy to detect subsequent birth weight discordance is poor (Table 1). Despite having poor sensitivity to predict birth weight discordance (sensitivity of $18.8 \%$ with a specificity of $92.1 \%$ at 90th centile CRL discrepancy) discordant CRL discrepancy can be used to counsel prospective parents in view of possible discordant birth weights [2].

There is epidemiological evidence linking birth weight with early fetal size in singletons [3]. But most of the weight gain in the foetus occurs in the last three months of pregnancy. This is the most likely reason why the association between CRL discrepancy and birthweight discordance is weak.

\section{Conclusion}

CRL discrepancy is independent of chorionicity in twins. Fetal loss is more common in monochorionic twins, but birth weight discordance is not. CRL discrepancy is correlated to subsequent pregnancy loss and birth weight discordance, but the clinical utility of this observation is limited. The difference in twin CRL at 1114 weeks is likely to represent physiological variation in a majority of cases.

\section{References}

1. Sebire NJ, D’Ercole C, Soares W, Nayar R, Nicolaides KH. Intertwin disparity in fetal size in monochorionic and dichorionic pregnancies. Obsteterics and Gynaecology 1998; 91: 82-5.

2. Kalish RB, Chasen ST, Gupta M, Sharma G, Perni SC, Chervenak FA. First trimester prediction of growth discordance in twin gestations. American Journal of Obstetrics and Gynaecology 2003; 189: 706-9.

3. Smith GC, Smith MF, Mc Nay MB, Fleming JE. Firsttrimester growth and the risk of low birth weight. New England Journal of Medicine 1998; 339: 1817-22.

4. National Collaborating Centre for Women's and Children's Health. Antenatal Care - routine care for the healthy pregnant woman. NICE/RCOG Press 2008.

5. Tai J, Grobman WA. The association of crown-rump length discordance in twin gestations with adverse perinatal outcomes. American Journal of Obstetrics and Gynaecology 2007; 197: 369.e1-4.

6. Yalçin HR, Zorlu CG, Lembet A, Ozden S, Gökmen O. The significance of birth weight difference in discordant twins: a level to standardize? Acta obstetricia et gynaecologica Scandinavica 1998; 77: 28-31.

7. Amaru RC, Bush MC, Berkowitz RL, Lapinski RH, Gaddipati S. Is discordant growth in twins an independent risk factor for adverse neonatal outcome? Obstetrics and Gynaecology 2004; 103: 71-6.

8. Bhide A, Sankaran S, Sairam S, Papageorghiou AT, Thilaganathan B. Relationship of intertwin crown-rump length discrepancy to chorionicity, fetal demise and birthweight discordance. Ultrasound in Obstetrics and Gynaecology 2009; 34:131-5.

9. Salomon LJ, Cavicchioni O, Bernard JP, Duyme M, Ville Y. Growth discrepancy in twins in the first trimester of pregnancy. Ultrasound in Obstetrics Gynaecology 2005; 26: 512-6.

10. Kalish RB, Gupta M, Perni SC, Berman S, Chasen ST. Clinical significance of first trimester crown-rump length disparity in dichorionic twin gestations. American Journal of Obstetrics and Gynaecology 2004; 191: 1437-40.

11. Sepulveda W, Sebire NJ, Hughes K, Odibo A, Nicolaides $\mathrm{KH}$. The lambda sign at 10-14 weeks of gestation as a predictor of chorionicity in twin pregnancies. Ultrasound in Obstetrics and Gynaecology 1996; 7: 421-3.

12. Bora SA, Bourne T, Bottomley C, Kirk E, Papageorghiou AT. Twin growth discrepancy in early pregnancy. Ultrasound in Obstetrics and Gynaecology 2009; 34:38-42.

13. Machin GA. Why is it important to diagnose chorionicity and how do we do it? Best Practice and Research Clinical Obstetrics and Gynaecology 2004; 18: 515-30.

14. Grennert L, Persson PH, Gennser G, Gullberg B. Zygosity and intrauterine growth of twins. Obstetetrics and Gynaecolology 1980; 55: 684-7.

15. Dube' J, Dodds L, Armson A. Does chorionicity or zigosity predict adverse perinatal outcome in twins? American Journal of Obstetrics and Gynaecology 2002; 186: 579-83.

16. Vergani P, Locatelli A, Ratti M, Scian A, Pozzi E, Pezzullo JC, Ghidini A Preterm twins: What threshold of birth weight discordance heralds major adverse neonatal outcome? American Journal of Obstetrics and Gynaecology 2004; 191: 1441-5.

17. Demissie K, Ananth CV, Martin J, Hanley ML, Mac Dorman MF, Rhoads GG. Fetal and neonatal mortality among twin gestations in the United States: the role of intrapair birth weight discordance. Obstetrics and Gynaecololgy 2002; 100: 474-80.

18. Branum AM, Schoendorf KC. The effect of birth weight discordance on twin mortality. Obstetrics and Gynaecology 2003; 101: 570-4. 